Thorax (1976), 31, 595.

\title{
Primary cardiac Kaposi's sarcoma
}

\author{
DAVID A. LEVISON and PETER d'A. SEMPLE \\ Department of Pathology, Ninewells Hospital and Medical School, and Department of \\ Respiratory Diseases, Kings Cross Hospital, Dundee
}

\begin{abstract}
Levison, D. A. and Semple, P. d'A. (1976). Thorax, 31, 595-600. Primary cardiac Kaposi's sarcoma. We report the clinical, laboratory, and necropsy findings in a 14-year-old boy with a primary Kaposi's sarcoma of the heart. Primary cardiac Kaposi's sarcoma and angiosarcoma are compared, and the pathogenesis of Kaposi's sarcoma is discussed. Relevant literature is briefly reviewed.
\end{abstract}

Primary angiosarcoma of the heart is itself a rare tumour, with only 45 previously reported cases (Patt, Halkin, and Jaffe, 1974; Massachusetts General Hospital, 1975). Even rarer as a primary in the heart is that other vascular tumourKaposi's sarcoma, with only five previous reports (Choisser and Ramsey, 1939; Weller, 1940; Aegerter and Peale, 1942; Contreras, 1957; Gelfand, 1957). These two tumours have undoubtedly been confused in the past, and by presenting this case we hope to go some way towards clarifying the situation. Our patient (aged 14) is younger than any previously reported with either primary cardiac angiosarcoma or Kaposi's sarcoma; his right atrial tumour is histologically a typical Kaposi's sarcoma.

\section{CASE REPORT}

A 14-year-old boy was found to have a large heart in a chest radiograph, taken because of school contact with a case of active tuberculosis. A presumptive diagnosis of tuberculous pericardial effusion was made and he was admitted to hospital. There was no previous illness of note, and his only symptoms were dry cough, retrosternal discomfort, anorexia, and occasional vomiting during the preceding week. On examination he looked well without dyspnoea or cyanosis. The heart rate was 90 per minute with no pulsus paradoxus and systemic blood pressure 114/80 $\mathrm{mmHg}$. The area of precordial dullness was increased and the apex beat was impalpable. Heart sounds were soft with no murmurs. The liver edge was palpable $3 \mathrm{~cm}$ below the costal margin and was slightly tender. The jugular venous pressure was not raised.
Investigations on admission: erythrocyte sedimentation rate $17 \mathrm{~mm} / \mathrm{hr}$, haemoglobin $16.9 \mathrm{~g} / \mathrm{dl}$, white cell count $17 \cdot 5 \times 10^{9} / 1$ (neutrophil leucocytosis). Urea and electrolytes normal. SGOT $94 \mathrm{IU} / \mathrm{ml}$, HBD $268 \mathrm{IU} / \mathrm{ml}$, bilirubin $12 \mu \mathrm{mol} / 1$. Sputum negative for tubercle bacilli. Electrocardiogram showed sinus tachycardia (110 beats per minute), low voltage, and ventricular extrasystoles.

Tuberculous pericardial effusion still seemed the most likely diagnosis despite a negative Mantoux test. Rifampicin, $600 \mathrm{mg}$, isoniazid, $300 \mathrm{mg}$, and ethambutol, $800 \mathrm{mg}$, were started two days after admission. On the fifth day he became dyspnoeic and mildly cyanosed. Although the jugular venous pressure was still not visibly raised, the liver edge was now palpable $5 \mathrm{~cm}$ below the costal margin, and early cardiac tamponade was suspected. One litre of bloodstained pericardial fluid was aspirated with little benefit. Its protein content was $50 \mathrm{~g} / 1$. No tubercle bacilli were seen in a Ziehl-Neelsen stained film of the aspirate, and cytological examination showed only red cells, histiocytes, and lymphocytes.

Within a few hours of aspiration the patient became more cyanosed and dyspnoeic. Serum bilirubin was found to be $71 \mu \mathrm{mol} / 1$, SGOT $2640 \mathrm{IU} / \mathrm{ml}$, and $\mathrm{HBD} 824 \mathrm{IU} / \mathrm{ml}$, suggesting possible liver damage; accordingly, rifampicin was withdrawn. By this time $Q$ waves had developed in chest leads VI-V4 of the electrocardiogram, suggesting coronary occlusion as another possible cause of enzyme rise. Lest further haemopericardium had been induced by needle trauma during pericardial aspiration, a further $300 \mathrm{ml}$ of sanguinous pericardial fluid was aspirated with no clinical benefit. The patient's condition rapidly deteriorated and 
he died 10 hours after the initial pericardial aspiration and five days after admission. Open cardiac massage was attempted. Necropsy was performed 18 hours later.

PATHOLOGICAL REPORT The most significant findings were confined to the heart. A thin film of fibrin extended over the inflamed epicardial surface but there was no residual effusion as the pericardial sac had been opened for cardiac massage. The anterior surface of the right atrium was pale in colour and lobulate in contour. Coronal section of the heart showed a lobulate haemorrhagic tumour, approximately $5 \mathrm{~cm}$ in diameter, filling most of the right atrium and firmly attached to the lateral, anterior, and septal walls (Fig. 1). A probe could just be passed from superior vena cava to inferior vena cava behind the tumour. No other tumour deposits were identified in the heart or elsewhere. Liver, spleen, and kidney showed the appearances of chronic venous congestion.

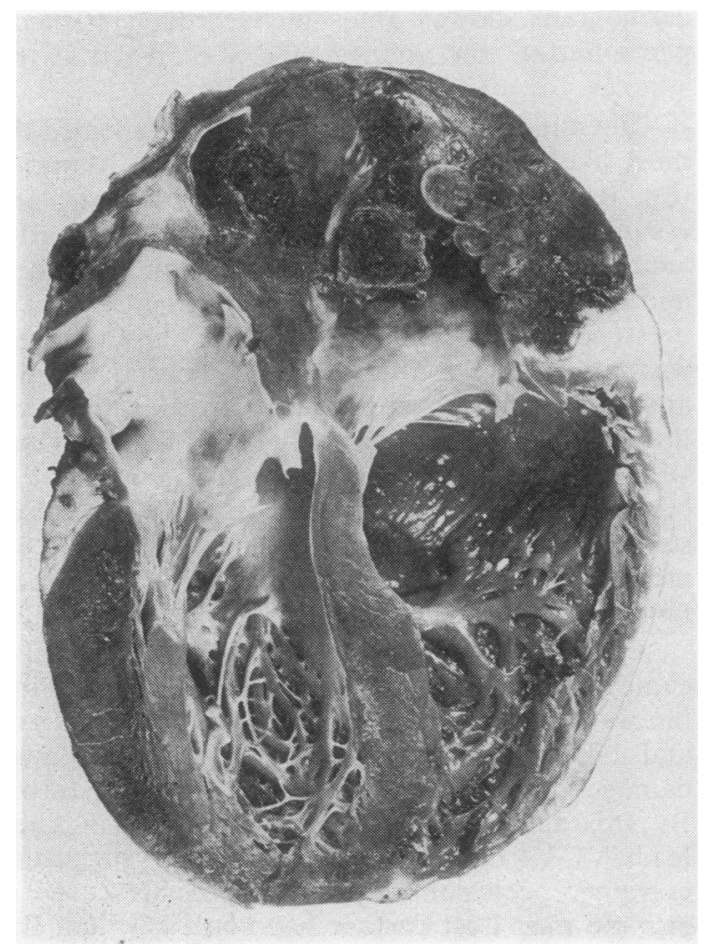

FIG. 1. Coronal section of heart viewed from behind. The dilated right atrium shows tumour invading and expanding its lateral wall and the interatrial septum and bulging into the lumen.
Sections of the right atrial tumour show highly vascular tumour invading the myocardiumo Its vessels vary markedly in size. In some areas, they are large, dilated, and lined by a single layeo of uniform plump endothelial cells, while in others they are mere slit-like spaces with no. obvious endothelial lining. Spaces between the vessels are filled by sheets of polyhedral andt spindle cells with hyperchromatic nuclei and il defined cytoplasm (Figs 2 and 3). Among these cells are several mitotic figures. There are extent sive areas of haemorrhage and necrosis with numerous macrophages, some containing haemosiderin, as well as foci of neutrophils an\& lymphocytes.

Special stains show little mucin and collagen but a reticulin stain shows appearances similar to those reported in 1939 by Choisser and Ramse in their cases of primary cardiac Kaposi's sarg coma. There is the same pattern varying from fine, lace-like fibres to dense, broad, branching processes. Most of the vascular spaces appear to be completely surrounded by reticulin.

Electron microscopy (Fig. 4) shows that the majority of the tumour cells have pale nucle with oval or irregular outlines, fine chromatin and prominent nucleoli. Their cytoplasm containg scanty organelles and occasional pieces of mem brane-bound and sometimes laminated debris These cells line small vascular spaces, some of which contain red cells. Some of the tumour celle are separated by dense material, possibly basemenit membrane. Also present are numerous neutroph $\vec{f}$ polymorphs, cells with shrunken darker nuclêt (probably dying), much fibrin, and cell debris.

Sections of the other organs show the appear ances of chronic venous congestion, the only unis expected finding being the presence of fairly extensive focal chronic thyroiditis.

\section{DISCUSSION}

Kaposi's sarcoma is best known in Africans and usually presents with the syndrome of lymphoedema, multiple cutaneous tumours, and lympho adenopathy with ultimate visceral involvements Cardiac lesions in this form of the disease are recognized, being present in five out of 19 cases necropsied by Lothe and Murray (1962).

Of much greater rarity are those tumours previously reported as primary Kaposi's sarcom of the heart in both Negroes and Caucasiars (Choisser and Ramsey, 1939; Weller, 194\% Aegerter and Peale, 1942; Contreras, 1957; Ge $\mathbb{P}$ fand, 1957). However, there are those (Glances 


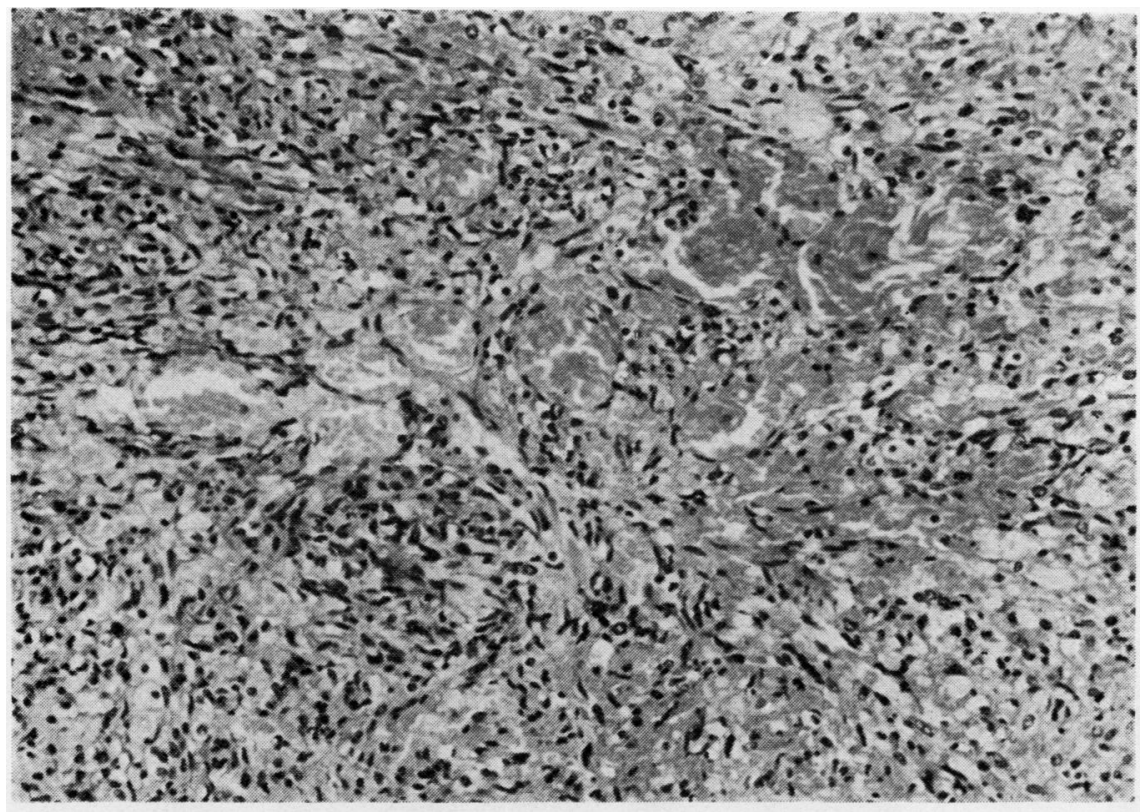

FIG. 2. Right atrial tumour. The mixed vascular and cellular pattern is shown. Thin-walled vessels stuffed with red cells are best shown to the left of centre ( $H$ and $E \times 240)$.

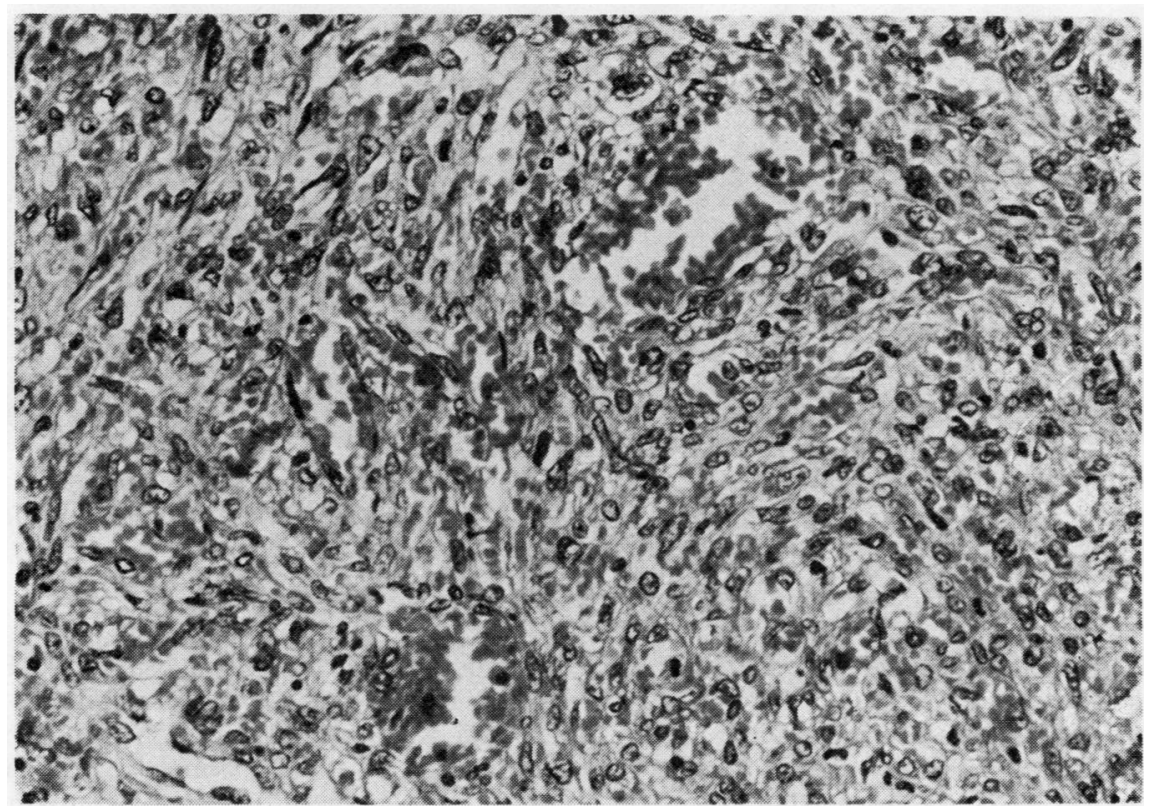

FIG. 3. A more solid part of the tumour. Abundant spindle cells, many lining capillary size vessels, separate larger vascular spaces $(H$ and $E \times 300$ ). 


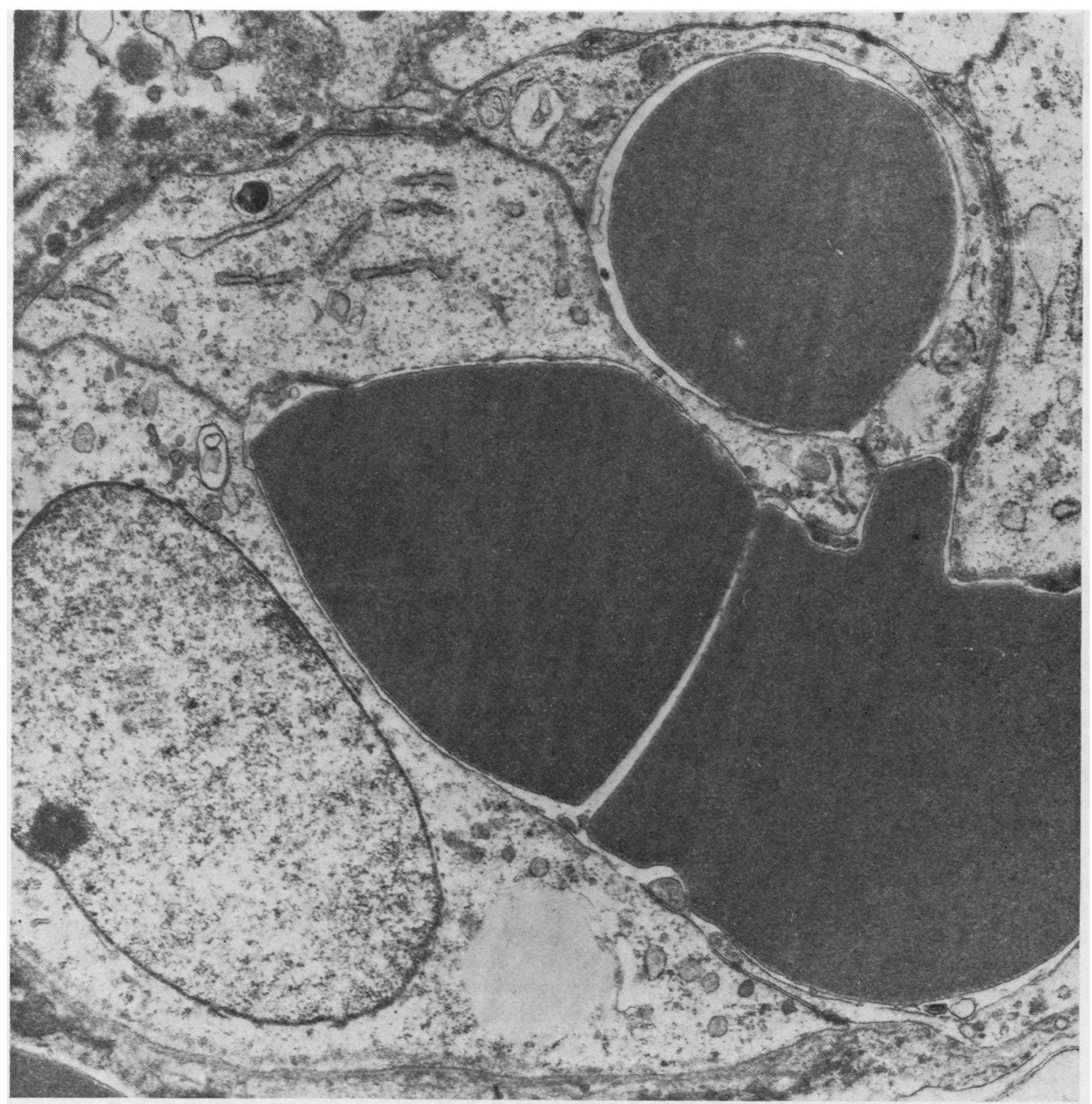

FIG. 4. Electron micrograph of the tumour. Three red blood cells lie in the lumen of a tumour capillary. The tumour cells have pale cytoplasm containing few organelles and fragments of membranous debris; one tumour cell nucleus uith prominent nucleolus is shown $(\times 15000)$.

Morales, and Roberts, 1968) who believe that none of these cases merits distinction from other forms of angiosarcoma 'on the basis of published photographs'. On this basis, there is some difficulty in separating Kaposi's sarcoma from other forms of angiosarcoma, but this is due at least partly to some cases of histologically typical Kaposi's sar- coma being reported as angiosarcoma (Hewer and Kemp, 1936). Perhaps the possibility of Kaposi's ?sarcoma was not actively considered because of $\frac{0}{0}$ the absence of typical skin lesions. Glancy et al. $\overrightarrow{\mathbb{D}}$ (1968) even suggest that cardiac involvement by $\frac{?}{\mathbb{D}}$ Kaposi's sarcoma should not be diagnosed in the absence of skin lesions. 
But the histological criteria for the diagnosis of Kaposi's sarcoma are well established (Murray and Lothe, 1962; Evans, 1968) and widely agreed. The tumour consists of a variable mixture of vascular components and spindle cells. The vascular component usually includes dilated blood vessels as in cavernous haemangioma and numerous capillary sized vessels. The large vascular spaces are often incompletely lined, but the capillary vessels are nearly always well formed. Seldom do the vessels contain piled up masses of endothelial cells so characteristic of angiosarcoma. The other important component, the spindle cells, may dominate the histological picture. Within the spindle-cell tissue are slits and clefts bounded by spindle cells rather than obvious endothelium, the clefts of ten containing erythrocytes (appearances similar to those illustrated in Fig. 3). Foci of lymphocytes, plasma cells, and macrophagessome containing haemosiderin-are of ten present.

Angiosarcoma, on the other hand, is generally composed of anastomosing channels lined by luxuriant and atypical epithelium (Evans, 1968). Occasionally the lining consists of a single row of round, polygonal or fusiform cells, but often its cells proliferate to form heaped up masses several layers thick. Freely anastomosing channels may give rise to a papillary pattern while in the more cellular areas the neoplastic endothelial cells accumulate in masses within closely opposed vessels to give the impression of a solid tumour lacking vasoformative tendencies. An inflammatory infiltrate, as seen in Kaposi's sarcoma, is not a common feature.

The histological findings in the present 14 -yearold boy with a primary cardiac tumour, described in detail above, are typical of Kaposi's sarcoma. So too are the appearances illustrated by Lothe and Murray (1962) from a case of cardiac involvement without skin lesions-previously reported without histological illustration by Gelfand (1957). This latter case is one of 496 cases of Kaposi's sarcoma seen by these authors and as such is very strong supportive evidence for the existence of a primary cardiac form of the disease.

Electron microscopy has not apparently been done previously on a case of primary Kaposi's sarcoma of the heart, but our observations are similar to those of Pepler and Theron (1962) who examined classic skin lesions. However, there is no general agreement with their view that the tumour is derived from Schwann cells. Laminated structures are present in the cytoplasm of this boy's tumour cells, but we interpret these as cell debris rather than axis cylinders.
Studies on the pathogenesis of Kaposi's sarcoma have produced conflicting results (Lancet, Editorial, 1967). Histochemical, cultural, and electron microscope studies have not finally resolved the nature and origin of the spindle cells. Schwann cells have been proposed by some authors but excluded by others. A 'reticuloendothelial' origin now seems to be most popular. Of considerable interest is the apparent association, in temperate climates at least, of Kaposi's sarcoma with a lymphomatous, leukaemic or other primary neoplasm (Lancet, Editorial, 1967). One possibility raised by this association is that a defect exists in the normal 'immune surveillance mechanism'. The only hint of any immunological disorder in our case is the presence of extensive focal chronic thyroiditis of the kind usually attributed to an autoimmune pathogenesis. Another possible clue to the aetiology of Kaposi's sarcoma is its peculiar geographic distribution in certain parts of Africa. This, particularly in view of the recent developments in the study of Burkitt's lymphoma, raises the possibility of an environmental agent; though a virus aetiology has long been suggested, evidence is lacking.

In conclusion, this case illustrates several features common to primary cardiac angiosarcoma and Kaposi's sarcoma such as the young age group, site of origin in the right atrium, presentation with pericardial effusion and cardiac failure, and the rapidly fatal outcome. It underlines the fact that Kaposi's sarcoma occasionally occurs in the heart in the absence of typical skin lesions.

We shculd like to thank Dr. R. N. Johnston for permission to report this case, Dr. E. Olsen for reviewing the histology and encouraging us to publish, and Mr. R. S. Fawkes for the photographs.

\section{REFERENCES}

Aegerter, E. E. and Peale, A. R. (1942). Kaposi's sarcoma: a critical survey. Archives of Patho$\log y, 34,413$.

Choisser, R. M. and Ramsey, E. M. (1939). Angioreticuloendothelioma (Kaposi's disease) of the heart. American Journal of Pathology, 15, 155.

Contreras, R. (1957). Angiosarcoma de Kaposi, primario del corazón: revision de la literatura y descripción del sexto caso. Archivos de Instituto de Cardiologia de Mexico, 27, 463.

Evans, R. W. (1968). Histological Appearances of Tumours, 2nd edition. Livingstone, Edinburgh and London.

Gelfand, M. (1957). Kaposi's haemangiosarcoma of the heart. British Heart Journal, 19, 290. 
Glancy, D. L., Morales, J. B., Jr., and Roberts, W. C. (1968). Angiosarcoma of the heart. American Journal of Cardiology, 21, 413.

Hewer, T. F. and Kemp, R. P. (1936). Malignant haemangio-endothelioma of the heart: report of a case. Journal of Pathology and Bacteriology, 43, 511.

Lancet (1967). Mysterious sarcoma. (Editorial). Lancet, 2, 1290.

Lothe, F. and Murray, J. F. (1962). Kaposi's sarcoma: autopsy findings in the African. Acta Unio Internationalis Contra Cancrum, 18, 429.

Massachusetts General Hospital Case record No. 35 (1975). New England Journal of Medicine, 293, 494.

Murray, J. F. and Lothe, F. (1962). The histopathology of Kaposi's sarcoma. Acta Unio Internationalis Contra Cancrum, 18, 413.
Patt, Y. Z., Halkin, H., and Jaffe, R. (1974). Primary cardiac angio-sarcoma. Israel Journal of Medical Sciences, 10, 525.

Pepler, W. J. and Theron, J. J. (1962). An electronmicroscope study of Kaposi's haemangiosarcoma. Journal of Pathology and Bacteriology, 83, 521.

Weller, G. L., Jr. (1940). The clinical aspects of $\mathcal{E}$ cardiac involvement (right auricular tumor) in $\vec{\circ}$ idiopathic hemorrhagic sarcoma (Kaposi's disease). Annals of Internal Medicine, 14, 314.

Requests for reprints to: Dr. D. A. Levison, Depart- ir ment of Pathology, Ninewells Hospital and Medical o School, Dundee, Scotland. 